\title{
Change in Lung Function over Time in Male Metropolitan Firefighters and General Population Controls: A 3-year Follow- up Study
}

\author{
Tjard R. Schermer ${ }^{1,2}$, Winifred MALbon ${ }^{3}$, Robert AdAMs ${ }^{4}$, Michael Morgan $^{5}$, \\ Michael SMith ${ }^{6}$ and Alan J. CROCKetT ${ }^{7,8}$
}

${ }^{1}$ Discipline of General Practice, School of Population Health, The University of Adelaide, Australia, ${ }^{2}$ Department of Primary and Community Care, Radboud University Nijmegen Medical Centre, The Netherlands, ${ }^{3}$ Discipline of General Practice, School of Population Health, The University of Adelaide, Australia, ${ }^{4} \mathrm{Health}$ Observatory, Discipline of Medicine, The University of Adelaide, The Queen Elizabeth Hospital Campus, Australia, ${ }^{5}$ South Australian Metropolitan Fire Service, Adelaide Fire Station, Australia, ${ }^{6}$ South Australian Metropolitan Fire Service, Australia, ${ }^{7}$ Discipline of General Practice, School of Population Health, The University of Adelaide, Australia and ${ }^{8}$ School of Health Sciences, University of South Australia, Australia

\begin{abstract}
Change in Lung Function over Time in Male Metropolitan Firefighters and General Population Controls: A 3-year Follow-up Study: Tjard R. Schermer, et al. Discipline of General Practice, School of Population Health, The University of Adelaide, Australia-Objectives: Previous studies in firefighters have been contradictory regarding their course of lung function over time. The aim of this ongoing study is to investigate how changes in lung function over time in male metropolitan firefighters compare with those in population controls, and to explore associations between firefighters' use of personal respiratory protection devices during occupational exposures and their risk of accelerated lung function decline. Methods: $A$ prospective comparison of $\mathrm{FEV}_{1}$ (forced expiratory volume in 1 second) and FVC (forced vital capacity) was performed between 281 firefighters and 933 population controls. Logistic regression models were used to compare changes from baseline of $F V_{1}$ and FVC after 3 years and risk of accelerated decline between the cohorts. Within the firefighter cohort, risk of accelerated decline was compared between subgroups based on use of respiratory protection devices. Results: Controls showed similar mean annual declines for $\mathrm{FEV}_{1}$ and FVC across age categories, whereas firefighters aged $<45$ years showed increasing values over time $(p=0.040)$. Firefighters had a lower odds of accelerated FEV1 decline compared with controls (OR=0.60, 95\% Cl
\end{abstract}

Received Aug 9, 2012; Accepted May 10, 2013

Published online in J-STAGE Jun 24, 2013

Correspondence to: T.R. Schermer, Primary Care Respiratory Research Unit, Discipline of General Practice, School of Population Health, The University of Adelaide, Adelaide, SA 5005 Australia (e-mail: tjaarda.schermer@adelaide.edu.au)
$0.44 ; 0.83)$, but firefighters who never or rarely used respiratory protection during fire knockdown had a higher odds of accelerated $\mathrm{FEV}_{1}$ decline compared with those who used it often or frequently $(\mathrm{OR}=2.20,95 \% \mathrm{Cl}$ 1.02; 4.74). Conclusions: Younger generations of firefighters showed an increase in lung function relative to older colleagues, while population controls consistently showed decline of lung function across all ages. Firefighters who reported to be incompliant in using respiratory protection showed an increased risk of accelerated $\mathrm{FEV}$, decline.

(J Occup Health 2013; 55: 267-275)

Key words: Firefighters, Follow-up studies, Male, Occupational diseases, Respiratory function tests, Smoking/adverse effects

Despite personal protection measures, firefighters may be at increased risk of adverse health effects due to exposure to smoke and other potentially harmful substances during their professional duties. In the past years, safeguarding firefighters' (respiratory) health has received increasing attention in Australia and elsewhere, from a research ${ }^{1)}$ as well as governance ${ }^{2)}$ point of view. Providing respiratory protection devices to firefighters has become standard policy in many fire departments around the world, although the devices may not always be optimally used ${ }^{3)}$. The importance of assessing physical fitness and performance when monitoring firefighters' health and selecting new recruits has also increased ${ }^{4,5}$.

Previous investigations have demonstrated that firefighters may show increased bronchial hyperrespon- 
siveness and reduced lung function after occupational exposure $^{3,6-8)}$. Studies looking at changes in firefighters' lung function over a prolonged period of time are scarce and have shown conflicting results, some indicating accelerated lung function decline ${ }^{9)}$ whereas others did not ${ }^{10-12)}$.

Only two previous studies have compared course of lung function between firefighters and general population controls ${ }^{13,14)}$. Because both these studies were conducted well over fifteen years ago and firefighters' working conditions have changed considerably during the past decades, their applicability to present-day generations of firefighters is likely to be limited.

The aim of the study reported in this paper was therefore to explore how changes in lung function over time in male metropolitan firefighters compare with those in male general population controls. In addition, we studied associations between firefighters' use of personal respiratory protection devices during occupational exposures and their risk of accelerated lung function decline.

\section{Subjects and Methods}

\section{Design and study populations}

The study was a prospective comparison between two existing cohorts of study subjects, i.e., a cohort of South Australian male metropolitan firefighters ${ }^{15)}$ and a reference cohort of South Australian males randomly selected from the general population ${ }^{16)}$.

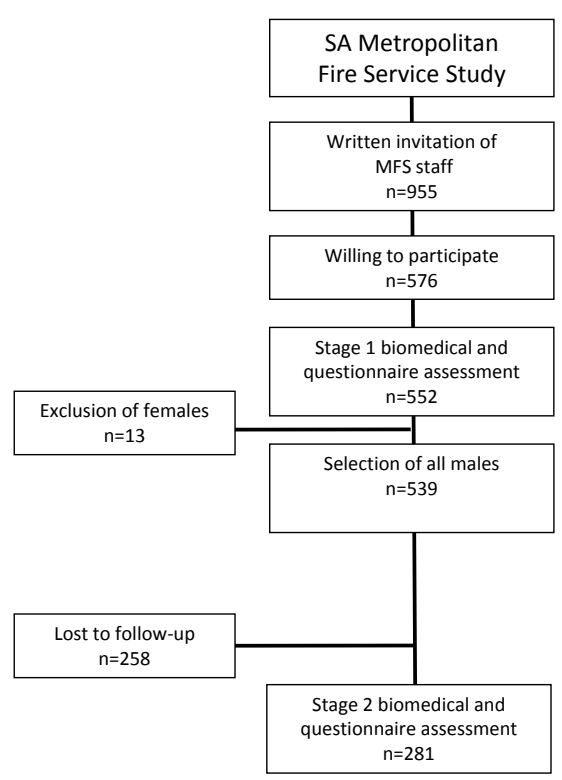

Data collection for the ongoing South Australian Metropolitan Fire Service (SAMFS) study commenced in August 2007 and was completed in April 2011. At the start of the study, the SAMFS maintained staff that included 729 full-time and 226 retained firefighters, all but one $(99.6 \%)$ Caucasians. At baseline, $56 \%$ $(n=539)$ of the male staff volunteered to be tested for the study, and $281(52 \%)$ of them could be reassessed for Stage 2 (Fig. 1). In reality, the retained firefighters are in country locations and are difficult to access. The participation rate amongst the metropolitan firefighters was about $74 \%$.

Males from the North West Adelaide Health Study (NWAHS $)^{17)}$ served as population controls for the comparison of the firefighters' course of lung function over time. The NWAHS is an ongoing longitudinal cohort study in 4,060 randomly selected adults, among them 1,988 males. For the current study, we used Stage 1 and Stage 2 NWAHS data (collected between February 2000 and June 2003, and between May 2004 and February 2006, respectively). Details of sampling, recruitment and measurement procedures used in the NWAHS study can be found elsewhere ${ }^{16,17)}$. Figure 1 shows the recruitment and follow-up for the NWAHS study and the selection for the comparison with the firefighters. A total of $933(70 \%)$ NWAHS male subjects $(95.5 \%$ Caucasians) could be reassessed for Stage 2 of the study.

The NWAHS was funded by the University of

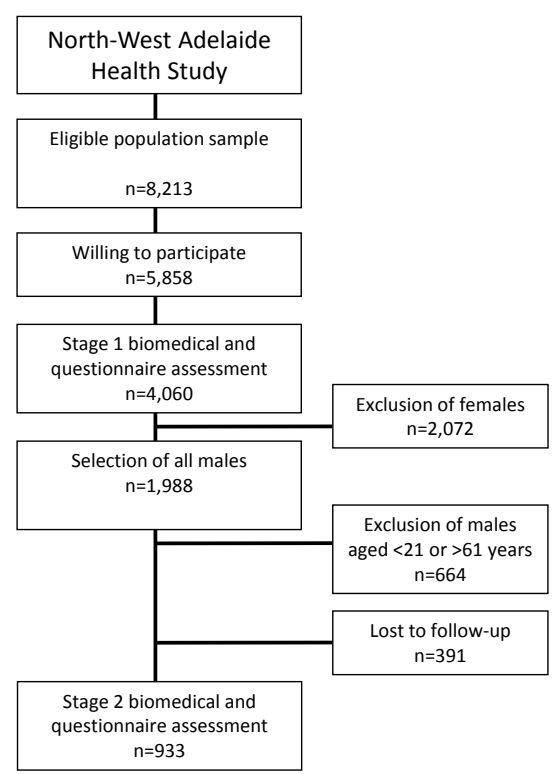

Fig. 1. Participant recruitment and follow-up in the MFS firefighters and NWAHS* population control cohorts

*Details of recruitment for the NWAHS cohort taken from the paper of Grant et al. ${ }^{17}$. ${ }^{\dagger}$ Age range in the firefighter cohort. MFS: Metropolitan Fire Service. NWAHS: North West Adelaide Health Study. 
Adelaide Faculty of Medicine and the Human Services Research Initiatives Projects of the SA Department of Health. Approval for the NWAHS was obtained from the Ethics Committees of the North West Adelaide Health Service, the University of Adelaide and the University of South Australia. The current analysis was funded by the SAMFS and the University of Adelaide and received ethics approval from the University of Adelaide Human Research Ethics Committee (H-057-2007). All study participants gave their informed consent.

\section{Measurements}

Change in $\mathrm{FEV}_{1}$ (forced expiratory volume in one second) over time served as the primary outcome for the comparison between the firefighters and general population controls. Change in FVC (forced vital capacity) was studied as a secondary outcome. Spirometry in the firefighters was performed using a MasterScreen ${ }^{\circledR}$ spirometer (Viasys Healthcare/ Cardinal Health, Würzburg, Germany) following 2005 recommendations for spirometry ${ }^{18)}$. Spirometry in the NWAHS was performed using a MicroLab ${ }^{\circledR}$ 2000 spirometer (Micro Medical/Cardinal Health, Dublin, OH, USA) following 1987 recommendations ${ }^{19)}$. Reference lung function values from healthy Australian adult lifetime nonsmokers without adverse bronchial symptoms were used to calculate percentage predicted values ${ }^{20)}$.

Information regarding smoking and doctordiagnosed respiratory and other medical conditions was ascertained by questionnaire in both cohorts. Additionally, in the firefighter cohort, we assessed occupational exposures and use of personal respiratory protection devices using a questionnaire, in which the firefighters reported if and how frequently they had been involved in common firefighting tasks (i.e., knockdown, overhaul, fire investigation, hazmat investigation) in the last 12 months. We also inquired how often the firefighters had worn respiratory protection during these tasks in that same period (never, rarely (i.e., less than $40 \%$ of the time), some of the time (40 to $60 \%$ ), often (60 to $80 \%$ ), frequently (80 to $100 \%$ ), respectively). The SAMFS has been using various types of compressed air/decant systems since the early 1970s. From 1997 until present (so during the observation period of the current study), the SAMFS has used AirMaxx self-contained breathing apparatus systems (MSA Auer, Berlin, Germany) for respiratory protection of their firefighters.

\section{Statistical analysis}

Data were analyzed using SPSS ${ }^{\circledR}$, version 19.0.0 (SPSS Inc., Chicago, IL, USA). The Student's $t$-test and $\chi^{2}$ test were used to compare baseline character- istics between the subjects in the longitudinal analyses and those who dropped out. Change in body weight (kg/year) was compared between firefighters and controls using the median test. Study subjects were categorized into six age categories based on their baseline age: $<35,36-40,41-45,46-50,51-55$ and 56-62 years. In order to incorporate the "clinical relevance" of change in $\mathrm{FEV}_{1}$ over time in our study subjects, accelerated $\mathrm{FEV}_{1}$ decline was defined as $>0.050 l /$ year, which is the average annual $\mathrm{FEV}_{1}$ decline for Australian males who are current heavy smokers $^{21)}$.

A GLM repeated measures model containing study stage (i.e., baseline or follow-up measurement), cohort (MFS or NWAHS), age category and their two and three way interaction terms was used to analyze differences between changes in $\mathrm{FEV}_{1}$ in firefighters and population controls over time. History of chronic respiratory disease and change in body weight between baseline and follow-up measurement ${ }^{22}$ were added to the model as potential confounders. Because of the small number of current smokers in the firefighter cohort $(n=26)$ and the well-known effect of smoking in causing accelerated $\mathrm{FEV}_{1}$ decline $^{23)}$, this analysis was limited to the nonsmokers in the firefighter cohort as well as in the NWAHS population control cohort.

A logistic regression model, again with interaction terms, was used to compare the odds of accelerated $\mathrm{FEV}_{1}$ decline between firefighters and controls. Within the firefighter cohort, the odds of accelerated $\mathrm{FEV}_{1}$ decline was compared between subgroups based on self-reported use of respiratory protection during knockdown. The logistic regression model included use of respiratory protection (never or rarely, some of the times, often or frequently), baseline smoking status (current smoker, current nonsmoker), age category ( $<45$ years; $\geq 46$ years), and weight change (in $\mathrm{kg} / \mathrm{year}$ ). Again, because of the small number of smokers, interaction between use of respiratory protection and smoking status was not included in the model. In all analyses, statistical significance was defined as $p<0.05$. Ninety-five percent confidence intervals (95\%CIs) were calculated when appropriate.

\section{Results}

Characteristics of study cohorts

Average duration of follow-up was 2.9 (SD 0.3) years for the firefighters and 3.5 (SD 1.1) years for the controls. Table 1 shows characteristics for the firefighters and the NWAHS controls who entered the longitudinal analysis and for those lost to followup. In both cohorts, baseline $\mathrm{FEV}_{1}$ and FVC and their $\%$ predicted values were higher in subjects who entered the longitudinal analyses compared with those 
Table 1. Baseline characteristics for the male firefighters and NWAHS controls who entered the longitudinal analysis and for those lost to follow-up. Values are means (standard deviation) unless states otherwise

\begin{tabular}{|c|c|c|c|c|c|c|}
\hline & \multicolumn{2}{|c|}{ Firefighters } & \multicolumn{3}{|c|}{ NWAHS controls } & \multirow[b]{2}{*}{$p$ value } \\
\hline & $\begin{array}{l}\text { In longitudinal } \\
\text { analysis } \\
(\mathrm{n}=281)\end{array}$ & $\begin{array}{l}\text { Lost to } \\
\text { follow-up } \\
(n=258)\end{array}$ & $p$ value & $\begin{array}{l}\text { In longitudinal } \\
\text { analysis } \\
(\mathrm{n}=933)\end{array}$ & $\begin{array}{l}\text { Lost to } \\
\text { follow-up } \\
(\mathrm{n}=379)\end{array}$ & \\
\hline Age (years) & $43.3(8.0)$ & $43.8(9.0)$ & $0.938^{\dagger}$ & $42.7(9.8)$ & $44.5(13.2)$ & $0.017^{\dagger}$ \\
\hline Height (m) & $1.81(0.06)$ & $1.79(0.06)$ & $0.022^{\dagger}$ & $1.77(0.07)$ & $1.75(0.07)$ & $<0.001^{\dagger}$ \\
\hline Weight (kg) & $89.4(11.4)$ & $89.3(10.9)$ & $0.752^{\dagger}$ & $88.0(16.2)$ & $85.3(16.9)$ & $0.009^{\dagger}$ \\
\hline $\begin{array}{l}\text { Body mass index } \\
<25 \mathrm{~kg} / \mathrm{m}^{2}, \mathrm{n}(\%) \\
25-30 \mathrm{~kg} / \mathrm{m}^{2}, \mathrm{n}(\%) \\
\geq 30 \mathrm{~kg} / \mathrm{m}^{2}, \mathrm{n}(\%)\end{array}$ & $\begin{array}{l}66(24) \\
169(60) \\
46(16)\end{array}$ & $\begin{array}{l}51(20) \\
159(62) \\
48(19)\end{array}$ & $0.794^{\$}$ & $\begin{array}{l}242(26) \\
432(46) \\
267(28)\end{array}$ & $\begin{array}{l}120(31) \\
152(40) \\
111(29)\end{array}$ & $0.061^{\$}$ \\
\hline $\begin{array}{l}\text { Smoking status, } \mathrm{n}(\%)^{\ddagger} \\
\text { Current smokers } \\
\text { Former smokers } \\
\text { Never smokers }\end{array}$ & $\begin{array}{c}26(9) \\
64(23) \\
190(68)\end{array}$ & $\begin{array}{l}28(11) \\
70(27) \\
160(62)\end{array}$ & $0.629^{\$}$ & $\begin{array}{l}254(27) \\
284(31) \\
394(42)\end{array}$ & $\begin{array}{l}134(35) \\
108(28) \\
141(37)\end{array}$ & $0.017^{\$}$ \\
\hline History of asthma, $\mathrm{n}(\%)$ & $37(13)$ & $30(12)$ & $0.569^{\$}$ & $126(14)$ & $53(14)$ & $0.816^{\$}$ \\
\hline $\begin{array}{l}\text { History of chronic bronchitis/emphy- } \\
\text { sema, } \mathrm{n}(\%)\end{array}$ & $16(6)$ & $13(5)$ & $0.873^{\$}$ & $250(27)$ & $98(26)$ & $0.724^{\$}$ \\
\hline $\mathrm{FEV}_{1}^{*}$ (liters) & $4.51(0.66)$ & $4.27(0.68)$ & $<0.001^{\dagger}$ & $3.72(0.70)$ & $3.52(0.76)$ & $<0.001^{\dagger}$ \\
\hline As $\%$ predicted & $104.9(11.8)$ & $101.3(12.0)$ & $<0.001^{\dagger}$ & $90.1(13.6)$ & $87.9(13.8)$ & $0.007^{\dagger}$ \\
\hline FVC* (liters) & $6.02(0.82)$ & $5.71(0.82)$ & $<0.001^{\dagger}$ & $4.57(0.81)$ & $4.32(0.88)$ & $<0.001^{\dagger}$ \\
\hline As $\%$ predicted & $111.3(11.4)$ & $108.2(11.4)$ & $0.001^{\dagger}$ & $89.2(12.3)$ & $87.0(12.7)$ & $0.005^{\dagger}$ \\
\hline
\end{tabular}

*Prebronchodilator values. ${ }^{\dagger}$ Student's $t$-test. ${ }^{\$}$ Chi-square test. ${ }^{*}$ Baseline smoking status was missing for 1 firefighter and 1 NWAHS control in the longitudinal analysis. $\mathrm{FEV}_{1}$, forced expiratory volume in 1 second; FVC, forced vital capacity; NWAHS, North West Adelaide Health Study.

who were lost to follow-up. In the NWAHS cohort, subjects who were current smokers were more likely to be lost to follow-up.

Baseline rate of current smoking in the firefighter cohort was about a third of the rate in the reference cohort ( $10 \%$ vs. $27 \% ; \chi^{2}$ test: $p<0.001$ ), while the rate of lifelong nonsmoking among the firefighters exceeded the rate among controls by $24 \%$ (Table 1 ). At follow-up, 10 firefighters (38\% of all baseline smokers in their cohort) and 51 controls (20\% of baseline smokers) reported that they quit smoking $\left(\chi^{2}\right.$ test: $p<0.001)$. In contrast, 3 firefighters $(1.1 \%$ of baseline nonsmokers) and 28 controls (4.2\%) reported to either have taken up or relapsed into smoking. The firefighters' weights increased by a median of 0.65 (interquartile range 1.50$) \mathrm{kg} / \mathrm{year}$, and the controls' weights increased by a median of $0.38(1.68) \mathrm{kg} / \mathrm{year}$ (median test: $p=0.087)$. Firefighters did not show a lower rate of doctor-confirmed asthma compared with controls (Table 1), but the rate of doctor-confirmed chronic bronchitis/emphysema was significantly higher among controls (6\% vs. $27 \% ; \chi^{2}$ test: $\left.p<0.001\right)$.
Change in lung function in firefighters and controls

Population controls showed very similar mean annual declines for $\mathrm{FEV}_{1}$ and $\mathrm{FVC}$ in all age categories (Fig. 2). Overall, the younger generations of firefighters (i.e., those $<45$ years) showed an increase in their average $\mathrm{FEV}_{1}$ and $\mathrm{FVC}$ values over time, while their colleagues from older generations either showed no change or a decline (Fig. 2). The repeated measures analysis showed that the difference in the annual change in $\mathrm{FEV}_{\text {, }}$ between the younger and older age categories differed between the firefighters and controls (interaction term stage cohort age category: $p=0.040$ ).

A total of 72 (26\%) firefighters and 363 (39\%) controls showed accelerated $\mathrm{FEV}_{1}$ decline (i.e., $>0.050 \mathrm{l} /$ year) during the observation period. Logistic regression analysis controlling for age, baseline smoking status and history of chronic respiratory conditions showed that firefighters had a lower odds of accelerated $\mathrm{FEV}_{1}$ decline compared with population controls (OR=0.60, 95\%CI 0.44 to $0.83 ; p=0.002$ ). 
Changes in lung function and use of respiratory protection in firefighters

At baseline, $78 \%$ of the firefighters had been on the job for $>6$ years. Of all the firefighters in the cohort, $80 \%$ reported involvement in fire knockdown in the past twelve months. On average, firefighters who had not been involved in knockdown were about five years older (47.2 (SD 7.0) years versus 42.5 (SD 8.0) years; Student's $t$-test: $p<0.001)$ than the ones that had been involved, were more often current or former smokers ( $46 \%$ vs. $29 \%$; $\chi^{2}$ test: $p=0.027$ ) and were more likely to have a history of chronic respiratory disease $(24 \%$ vs. $13 \% ; \chi^{2}$ test: $p=0.039$ ).

Firefighters involved in knockdown who reported never or rarely using their respiratory protection during that task $(n=50)$ were also more likely not to wear protection during other tasks that involve exposure to smoke or other potentially harmful substances (i.e., during overhaul, $87 \%, \chi^{2}$ test, $p<0.001$; during fire investigation, $73 \%, \chi^{2}$ test, $p=0.063$ ). Never or rarely using respiratory protection during fire knockdown was more common in older firefighters than in younger firefighters $(12 \%$ in those aged $\leq 40$ years, $27 \%$ in those aged 41 to 50 years and $40 \%$ in those aged $>51$ years $\left(\chi^{2}\right.$ test: $\left.p=0.039\right)$ ).

Figure 3 shows the annual change in lung function for the firefighters in relation to their involvement in knockdown and, if applicable, self-reported use of respiratory protection during knockdown. Logistic regression analysis controlling for smoking status, age and history of chronic respiratory disease showed that firefighters who reported never or rarely using their respiratory protection during fire knockdown had a higher odds of accelerated $\mathrm{FEV}_{1}$ decline compared with those who used it often or frequently $(\mathrm{OR}=2.20$, $95 \%$ CI 1.02 to $4.74 ; p=0.044)$. Firefighters who wore their respiratory protection some of the time seemed to have a higher odds of accelerated $\mathrm{FEV}_{1}$ decline, but this was not statistically significant $(\mathrm{OR}=1.71$, $95 \%$ CI 0.69 to $4.24 ; p=0.248$ ). The interaction term between age category and frequency of using respiratory protection devices during knockdown in relation to change in $\mathrm{FEV}_{1}$ came close to statistical significance $(\mathrm{OR}=1.96,95 \% \mathrm{CI} 0.91$ to $4.22 ; p=0.086)$. The logistic regression model also showed that the odds of accelerated $\mathrm{FEV}_{1}$ decline in firefighters who were current smokers was 4.59 (95\% CI 1.71 to 12.33) compared with their nonsmoking colleagues.

\section{Discussion}

In this study, we assessed the course of lung function in male metropolitan firefighters over a threeyear time period and compared this with males from a general population cohort. We found that younger generations of firefighters showed an increase in

\section{Panel A}

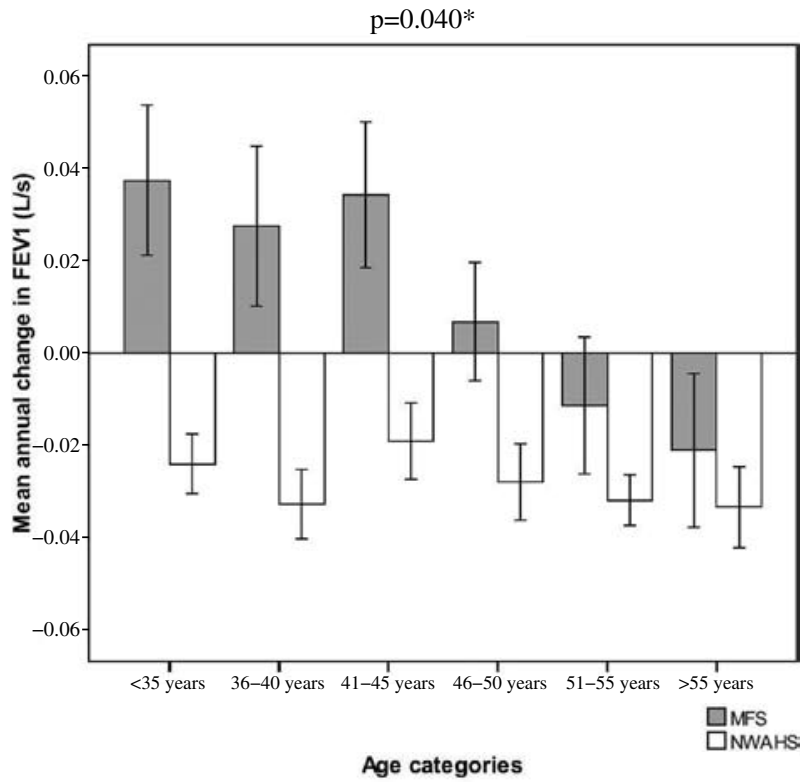

\section{Panel B}

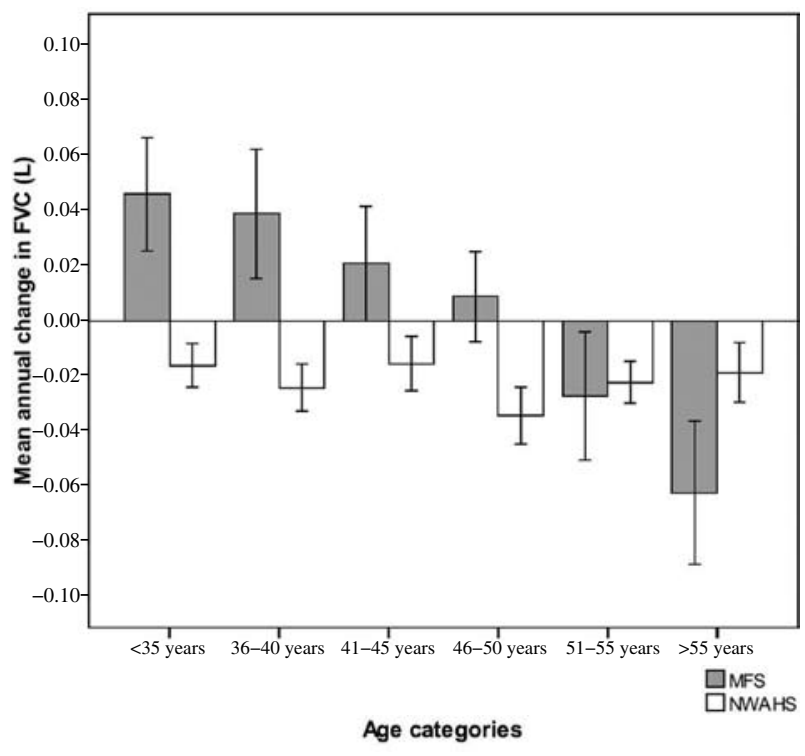

Fig. 2. Annual change in $\mathrm{FEV}_{1}$ (panel A) and FVC (panel B) by age category for nonsmoking firefighters $(n=254)$ and population controls $(n=678)$. Error bars indicate standard errors of the mean

$\mathrm{FEV}_{1}$, forced expiratory volume in 1 second; FVC, forced vital capacity. ${ }^{*}$ For interaction term cohort age category in relation to change in $\mathrm{FEV}_{1}$ over time.

their $\mathrm{FEV}_{1}$ and $\mathrm{FVC}$ values relative to older generations of firefighters, while the population controls consistently showed decline in $\mathrm{FEV}_{1}$ as well as FVC across all ages. Firefighters had a lower risk of accelerated $\mathrm{FEV}_{1}$ decline compared with population controls. Within the firefighter cohort, smokers and those who reported not or only occasionally using 


\section{Panel A}

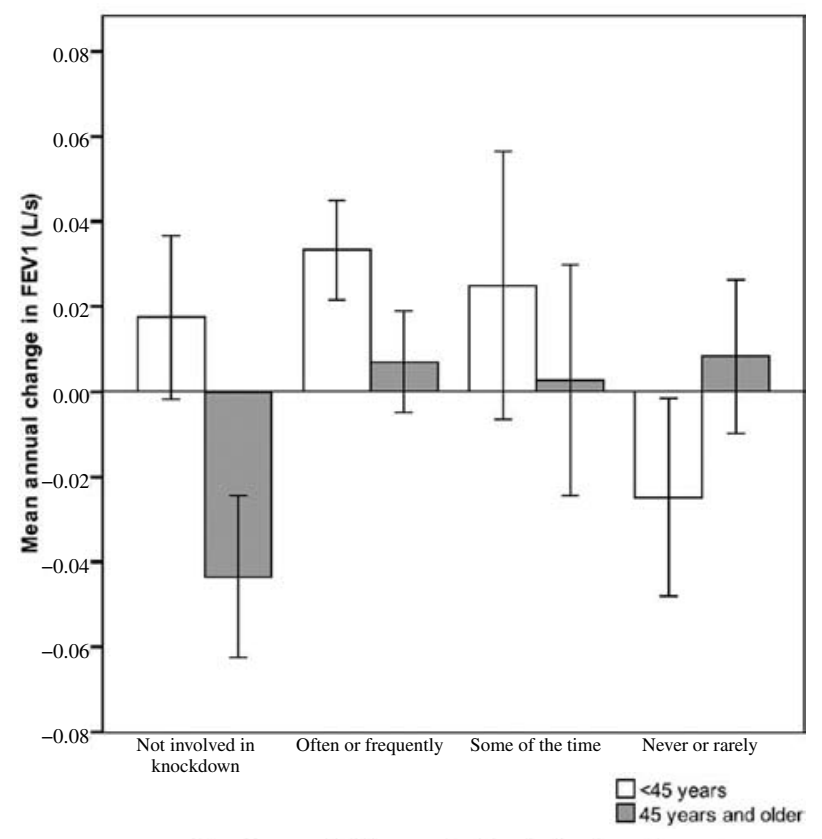

Wearing respiratory protection during knockdown

Panel B



Fig. 3. Annual change in $\mathrm{FEV}_{1}$ (panel A) and FVC (panel B) by age group and use of respiratory protection devices during knockdown in male firefighters $(n=281)$. Error bars indicate standard errors of the mean $\mathrm{FEV}_{1}$, forced expiratory volume in 1 second; FVC, forced vital capacity. their respiratory protection devices during fire knockdown showed an increased risk of accelerated FEV decline compared with those who used their respiratory protection more consistently.

\section{Comparison with existing literature}

Analysis of the baseline data of our firefighter cohort showed that those with the highest rate of selfreported exposure to dust, smoke and fire showed statistically significant lower $\mathrm{FEV}_{1}, \mathrm{FEV}_{1} \%$ predicted and FVC values compared with colleagues who reported being less exposed to these factors ${ }^{15}$. It has previously been shown that firefighters may be at increased risk of accelerated lung function decline, depending on their actual exposure to inhaled harmful substances during their professional duties ${ }^{13,24,25)}$. Rapid decline of lung function over time has been reported in a study in Baltimore City firefighters ${ }^{9)}$ and in firefighters who presented for pulmonary evaluation after having been involved in the rescue work at the World Trade Center (WTC) disaster ${ }^{26}$. On the other hand, a follow-up study conducted in England showed that, as a group, male firefighters showed a lower rate of lung function decline over time than control subjects $\operatorname{did}^{14)}$. Our comparison between firefighters and NWAHS general population controls supports the latter finding and adds that this phenomenon may be mainly attributable to an increase in lung function over time in younger (i.e., $<45$ years) firefighters rather than a decelerated rate of decline across all age groups. Although there is a body of literature showing that the respiratory system undergoes various anatomical and physiological changes with age and that after 20-25 years of age, aging is associated with progressive decline in lung function ${ }^{27,28)}$, this may be different for firefighters. Possible explanations for this are the selection of healthy and very fit men for service ("healthy worker effect") ${ }^{29,30)}$, the regular use of self-contained breathing apparatus systems ${ }^{14)}$, the strenuous physical demands that come with the job or a combination of these (and other) factors. Moreover, firefighters are likely to realize that physical training and looking after their (respiratory) health are a year-round commitment if they are to successfully meet the demands of their job ${ }^{31}$ - which seems to be reflected in the low smoking rate $(\sim 10 \%)$ in our firefighter cohort. Confirmation of our findings in another cohort of firefighters and/or comparison with other males selected based on their physical fitness (for instance, soldiers) who can be matched to firefighters is necessary. To further study the role of selfcontained breathing apparatus systems as a possible explanation of our findings, a comparison with professional divers could be made. But even by matching to more suitable controls, in the case of firefighters 
the physical fitness and activity cannot be "isolated" from the other potential explanations for the unexpected increase in lung function (e.g., frequent use of breathing apparatus and performing strenuous physical activity while using this equipment).

Our observation that a more frequent use of respiratory protection devices during fire knockdown and other potentially harmful tasks may prevent firefighters from having accelerated lung function decline is consistent with a report from the previously mentioned study in Baltimore firefighters, in which a correlation between the use of protective devices and rate of $\mathrm{FEV}_{1}$ decline was found ${ }^{9)}$. In contrast, analyses of longitudinal spirometry data of WTC rescue workers did not show an association between respirator use and $\mathrm{FEV}_{1}$ or $\mathrm{FVC}$ decline ${ }^{32)}$, which may be explained by the typical, very intense and enduring inhalation exposure of the rescue workers in the aftermath of the disaster ${ }^{33)}$ and the variety of respirator devices that were used $^{32)}$. Another interesting finding in our study was that the subgroup of older ( $>45$ year) firefighters who had not actively been involved in fire knockdown in the past year showed the fastest rate of lung function decline, which may indicate that they were exempted from the heavier physical tasks and/or protected against inhaled exposures due to impaired respiratory health.

\section{Strengths and limitations}

Two particular strengths of this study are the sizes of the firefighter and population control cohorts and the considerable follow-up time ( $\sim 3$ years) for both cohorts. Apart from the ongoing monitoring of WTC rescue workers ${ }^{26,34)}$, longitudinal studies in well-defined cohorts of firefighters like ours are rather scarce. At baseline, some selection may have occurred when recruiting firefighters for the study, as firefighters who suspected that their respiratory health could be compromised (for instance, as a consequence of smoking habits or awareness of limited physical fitness) may have been less likely to volunteer for the study. This may have caused some selection bias towards better general and respiratory health in the firefighter cohort.

The observed increase in lung function in the younger firefighters does at least suggest that strenuous physical activity can improve lung function over time, as it is likely that as a group firefighters perform more-and more frequent-strenuous activities and are more physically fit than age-matched population controls. Unfortunately, in the current study, we had no further documentation from standardized exercise testing, activity monitoring or otherwise about the firefighters' and controls' levels of physical fitness or physical activity.
Another limitation is the fact that we only had results of two spirometry tests at our disposal, whereas more frequent measurements would have enabled us to get more precise estimates of lung function changes in both cohorts ${ }^{35}$. However, the limited precision applies to the measurements in firefighters as well as in controls and therefore cannot explain the observed differences between the two groups. Spirometry in the North West Adelaide Health Study was performed using less strict criteria for judging acceptability and repeatability of forced blows ${ }^{19}$ compared with the SAMFS firefighter study ${ }^{18)}$. Although this difference in measurement procedures may have contributed to the observed differences in lung function indices in the two cohorts, it is rather unlikely that this factor can fully explain the substantial difference in $\mathrm{FEV}_{1}$ and FVC changes over time between the firefighters and population controls.

Our data about involvement in firefighter tasks and exposures to potentially harmful substances was limited to firefighters' self-reports only. Clearly, we would have preferred to have more comprehensive information regarding length of time spent in exposed jobs, number of responses and actual use of respiratory protection devices at our disposal, but in the current study, it was not feasible to collect this kind of data.

\section{Conclusions}

In this exploratory study, we observed an increase in lung function over time in younger generations of firefighters relative to older generations of firefighters, while general population controls consistently showed decline of lung function across all age groups. Overall, firefighters had a lower risk of accelerated $\mathrm{FEV}_{1}$ decline compared with population controls. These observations need to be verified in further studies with suitable age-matched controls. Within the firefighter cohort, smokers and those who reported not or only occasionally using their respiratory protection devices showed an increased risk of accelerated $\mathrm{FEV}_{1}$ decline compared with those who used their respiratory protection more consistently. This study supports improvement in the use of respiratory protection devices by firefighters, as well as monitoring firefighters' (respiratory) health over time.

Acknowledgments: Acknowledgment is made of the generosity of the South Australian Metropolitan Fire Service (SAMFS) firefighters and North West Adelaide Health Study (NWAHS) participants in the giving of their time and effort and of the contribution to the study by the SAMFS staff and the NWAHS research clinic and recruiting staff. Sarah Appleton is acknowledged for providing the authors access to the NWAHS data. The authors very much appreci- 
ate the preparatory work for the study performed by Guillaume Dujardin and Christine Holton, the statistical advice provided by Michelle Lorimer and the support in data entry and processing provided by Daniel Blakeley.

Conflict of interest: The authors declare that they have no conflict of interest.

\section{References}

1) De Vos A, Cook A, Devine B, Thompson PJ, Weinstein P. Effect of protective filters on fire fighter respiratory health during simulated bushfire smoke exposure. Am J Ind Med 2006; 49: 740-50.

2) Anonymous. AFAC Guidelines for Health and Fitness Monitoring of Australasian Fire and Emergency Service Workers. 2002.

3) Greven F, Krop E, Spithoven J, Rooyackers J, Kerstjens H, Heederik D. Lung function, bronchial hyperresponsiveness, and atopy among firefighters. Scand J Work Environ Health Scand J Work Environ Health 2011; 37: 325-31.

4) Michaelides M, Parpa K, Henry L, Thompson GB, Brown BS. Assessment of physical fitness aspects and their relationship to firefighters' job abilities. J Strength Cond Res 2011; 25: 956-65.

5) Peterson, M, Dodd D, Alvar B, Rhea MR, Favre M. Undulation training for development of hierarchical fitness and improved firefighter job performance. J Strength Cond Res 2008; 22: 1683-95.

6) Loke J, Farmer W, Matthay R, Putman CE, Smith GJ. Acute and chronic effects of fire fighting on pulmonary function. Chest 1980; 77: 369-73.

7) Large A, Owens G, Hoffman L. The short-term effects of smoke exposure on the pulmonary function of firefighters. Chest 1990; 97: 806-9.

8) Liu D, Tager I, Balmes J, Harrison RJ. The effect of smoke inhalation on lung function and airway responsiveness in wildland fire fighters. Am Rev Respir Dis 1992; 146: 1469-73.

9) Tepper A, Comstock G, Levine M. A longitudinal study of pulmonary function in fire fighters. Am J Ind Med 1991; 20: 307-16.

10) Musk A, Peters J, Wegman D. Lung function in fire fighters, I: a three year follow-up of active subjects. Am J Public Health 1977; 67: 626-9.

11) Musk A, Peters J, Bernstein L, Rubin C, Monroe CB. Pulmonary function in firefighters: a six-year follow-up in the Boston Fire Department. Am J Ind Med 1982; 3: 3-9.

12) Burgess J, Brodkin C, Daniell W, et al. Longitudinal decline in measured firefighter single-breath diffusing capacity of carbon monoxide values. A respiratory surveillance dilemma. Am J Respir Crit Care Med 1999; 159: 119-24.

13) Sparrow D, Bossé R, Rosner B, Weiss ST. The effect of occupational exposure on pulmonary function: a longitudinal evaluation of fire fighters and nonfire fighters. Am Rev Respir Dis 1982; 125:
319-22.

14) Horsfield K, Guyatt A, Cooper F, Buckman MP, Cumming G. Lung function in West Sussex firemen: a four year study. Br J Ind Med 1988; 45: 116-21.

15) Schermer $T$, Malbon $W$, Morgan $M$, et al. Lung function and health status in metropolitan firefighters compared to general population controls. Int Arch Occup Environ Health 2010; 83: 715-23.

16) Grant J, Taylor A, Ruffin R, et al. Cohort profile: The North West Adelaide Health Study (NWAHS). Int J Epidemiol 2009; 38: 1479-86.

17) Grant J, Chittleborough C, Taylor A, et al. The North West Adelaide Health Study: detailed methods and baseline segmentation of a cohort for selected chronic diseases. Epidemiol Perspect Innov 2006; 3: 4.

18) Miller M, Hankinson J, Brusasco V, et al. Standardisation of spirometry. Eur Respir J 2005; 26: 319-38.

19) American Thoracic Society. Standardization of spirometry - 1987 update. Statement of the American Thoracic Society. Am Rev Respir Dis 1987; 136: 1285-98.

20) Gore CJ, Crockett A, Pederson D, Booth ML, Bauman A, Owen N. Spirometric standards for healthy adult lifetime nonsmokers in Australia. Eur Respir J 1995; 8: 773-82.

21) James A, Palmer L, Kicic E, et al. Decline in lung function in the Busselton Health Study: the effects of asthma and cigarette smoking. Am J Respir Crit Care Med 2005; 171: 109-14.

22) Aldrich TK, Ye F, Hall CB, et al. Longitudinal pulmonary function in newly-hired, non-wtc-exposed FDNY firefighters: the first 5 years. Chest 2013; 143: 791-7.

23) Lee P, Fry J. Systematic review of the evidence relating FEV1 decline to giving up smoking. BMC Med 2010; 8: 84.

24) Loke J, Abrams C, Virgulto J. Lung function in fire fighters. Conn Med 1992; 56: 179-83.

25) Banauch G, Hall C, Weiden M, et al. Pulmonary function after exposure to the World Trade Center collapse in the New York City Fire Department. Am J Respir Crit Care Med 2006; 174: 312-9.

26) Weiden M, Ferrier N, Nolan A, et al. Obstructive airways disease with air trapping among firefighters exposed to World Trade Center dust. Chest 2010; 137: 566-74.

27) Janssens J, Pache J, Nicod L. Physiological changes in respiratory function associated with ageing. Eur Respir J 1999; 13: 197-205.

28) Sharma G, Goodwin J. Effect of aging on respiratory system physiology and immunology. Clin Interv Aging 2006; 1: 253-60.

29) Ide C. Reasons for rejection: why people fail to qualify as firefighters. Occup Med 1996; 46: 421-7.

30) Wagner N, Berger J, Flesch-Janys D, et al. Mortality and life expectancy of professional fire fighters in Hamburg, Germany: a cohort study 1950-2000. Environ Health 2006; 5: 27. 
31) Poston WS, Haddock CK, Jitnarin N, Janhke SA. A national qualitative study of tobacco use among career firefighters and department health personnel. Nicotine Tob Res 2012; 14: 734-41.

32) Feldman D, Baron S, Bernard B, et al. Symptoms, respirator use, and pulmonary function changes among New York City firefighters responding to the World Trade Center disaster. Chest 2004; 125: 1256-64.

33) Rom W, Reibman J, Rogers L, et al. Emerging exposures and respiratory health: World Trade Center dust. Proc Am Thorac Soc 2010; 7: 142-5.

34) Skloot G, Schechter C, Herbert R, et al. Longitudinal assessment of spirometry in the World Trade Center medical monitoring program. Chest 2009; 135: 492-8.

35) Wang M, Avashia B, Petsonk E. Interpreting periodic lung function tests in individuals: the relationship between 1- to 5-year and long-term FEV1 changes. Chest 2006; 130: 493-9. 